\title{
Sociedade TarJa Preta: uma crítica À medicalização DE CRIANÇAS E ADOLESCENTES
}

Por Gisele Toassa ${ }^{\star}$

CONSELHO REGIONAL DE PSICOLOGIA DE SÃO PAULO [CRP/SP]; GRUPO INTERINSTITUCIONAL QUEIXA ESCOLAR. Medicalização de crianças e adolescentes: conflitos silenciados pela redução de questões sociais a doenças de indivíduos. São Paulo: Casa do Psicólogo, 2010.

\section{Resumo}

Como breve análise do livro "Medicalização de crianças e adolescentes: conflitos silenciados pela redução de questões sociais a doenças de indivíduos", esta resenha contextualiza a importância da publicação na crítica contemporânea à invenção de (psico)patologias e tratamentos a elas destinados. O livro logra, de forma extremamente rigorosa, desconstruir as "bases cientificas" que sustentam o transtorno de déficit de atenção e hiperatividade (TDAH), mostrando como a indústria farmacêutica vem ocultando sistematicamente os profundos efeitos colaterais do princípio ativo destinado a tratá-lo (o metilfenidato, presente na Ritalina ${ }^{\circledR}$ e Concerta $\left.{ }^{\circledR}\right)$. Com textos de profissionais vinculados à saúde e educação, nas mais diferentes áreas do conhecimento, o livro representa uma notável coalizão de esforços em beneficio da promoção dos direitos de crianças e adolescentes.

Palavras-chave: medicalização; transtorno de déficit de atenção e hiperatividade; metilfenidato; educação infantil; problemas de aprendizagem

\section{BLACK LABEL SOCIETY: A CRITIQUE REGARDING THE MEDICALIZATION OF CHILDREN AND ADOLESCENTS}

\begin{abstract}
This text is a book's review towards the first edition of "Medicalization of children and adolescents: conflicts silenced by the reduction of social issues to diseases of individuals", which discusses the publication's relevance as a criticism of (psycho) pathologies and their treatments. The book succeeds in rigorously deconstructing the "science" that legitimates the attention deficit hyperactivity disorder (ADHD),

\footnotetext{
^ Psicóloga. Bacharel em Fonoaudiologia pela Universidade de São Paulo, com Mestrado em Educação pela Universidade Estadual Paulista Júlio de Mesquita Filho e Doutorado em Psicologia Escolar e do Desenvolvimento Humano pela Universidade de São Paulo. Atualmente, é Professora Adjunta da Universidade Federal de Goiás, Faculdade de Educação. Endereço: Universidade Federal de Goiás, Faculdade de Educação. R. 235, s/n - Setor Leste Universitário. Goiania, GO Brasil - Caixa-postal: 050011010. CEP: 74605-050

E-mail: gtoassa@gmail.com
} 
exposing how the pharmaceutical industry has been systematically concealing the profound collateral effects of the methylphenidate, the drug which treats it. The publication also presents papers by health and education practitioners, representing a remarkable effort directed to change the child/adolescent health care and education.

Keywords: medicalization; attention deficit hyperactivity disorder (ADHD); methylphenidate; child education; learning disorders

Imitando a embalagem de um medicamento de tarja preta, a capa planta nos seus leitores uma inquietude que o conteúdo do livro não chega a sanar - pelo contrário, expande e intensifica. "Medicalização de Crianças e Adolescentes: conflitos silenciados pela redução de questões sociais a doenças de indivíduos" ([CRP/SP]; GRUPO INTERINSTITUCIONAL QUEIXA ESCOLAR, 2010) é coletânea pioneira na abrangência da sua interdisciplinaridade, ação resultante de um amplo movimento de crítica social que, hoje, articula-se por meio do Fórum sobre Medicalização da Educação e da Sociedade. Com apresentação e quinze capítulos organizados em três partes (Introdução, Fundamentos do Diagnóstico e do Tratamento em Debate, Medicalização e Educação, Intervenções), apresenta estudos teóricos e de projetos de lei; um relato de experiência em clínica fonoaudiológica contendo alternativa à medicalização do processo de desenvolvimento da linguagem escrita; análise ficcional da rotina de um médico vinculado a atenção primária; relato de pesquisa sobre preconceito com professores e revisão bibliográfica nacional de estudos sobre a medicalização da aprendizagem de crianças em idade escolar. Qualifica-se como robusta iniciativa em defesa do direito à saúde e educação de crianças e adolescentes, fazendo-se essencial para profissionais de ambas as áreas, sem excetuar familiares e outros interessados na temática. Longe de constituir-se em análise exaustiva de coletânea tão diversificada, o objetivo desta resenha é expor o conceito de medicalização, sua expressão hegemônica na infância e na adolescência e os vínculos políticos que os sustentam.

Tesser (2006, p. 62) define a medicalização como: “expansão progressiva do campo de intervenção da biomedicina por meio da redefinição de experiências e comportamentos humanos como se fossem problemas médicos". Mais do que uso excessivo de medicamentos, consiste em uma lógica por meio da qual os indivíduos tendem a interpretar problemas de diversas raízes como se fossem fatos clínicos objetivos. A história da evolução deste complexo fenômeno no campo educacional desvela-se no capítulo 5, de Moysés e Collares. ${ }^{1}$ Exemplo de trabalho militante e cientificamente rigoroso, conjuga indignação e bom humor ao analisar os pseudoconceitos medicalizantes da educação, desde a assustadora "cegueira verbal congênita" (termo cunhado em 1896) aos palavrosos "transtornos por déficit de atenção e hiperatividade" (TDAH), tão populares nos dias de hoje. As autoras resumem estudos que, desde métodos anatomopatológicos até caríssimos exames de neuroimagem, acabaram pondo a descoberto o estatuto de normatividade social - e não científica - da medicalização do campo escolar. 
Entre os instrumentos atualmente destinados ao diagnóstico de TDAH, destacase o tragicômico teste SNAP IV - no qual "Mexer com as mãos ou os pés ou se remexer na cadeira" é qualificado como comportamento hiperativo.

Delineia-se, ainda, a inquietante proximidade entre indústria farmacêutica e Organizações Não-Governamentais voltadas ao "atendimento" da população de crianças e adolescentes portadores desses pseudotranstornos, supostamente tratada pelo metilfenidato (cujos nomes comerciais são Ritalina ${ }^{\circledR}$ e Concerta ${ }^{\circledR}$, e a sigla, MPH). As autoras mapeiam os efeitos colaterais do MPH, com uma informação estarrecedora: "O mecanismo de ação do MPH e das anfetaminas é exatamente o mesmo da cocaína: poderosos estimulantes que aumentam a atenção e a produtividade" (MOYSÉS; COLLARES, p. 97). Segundo as autoras, um dos riscos potenciais a longo prazo é adição à cocaína, como modo de substituição da droga legal ingerida durante a infância/adolescência. O contexto evoca-nos a película Requiem for a dream, de Darren Aronofsky (2000), que, mergulhandonos nas vivências kafkianas de quatro personagens, mostra como as tentativas de normalização da vida engendram criminalização e psiquiatrização, destruindo desejos e peculiaridades individuais. A protagonista, Sara Goldfarb, anseia por perder peso, recorrendo a anfetaminas para emagrecer. O silencioso acordo entre a indiferença do serviço de saúde e o sonho normatizador de Sara - tão próprio ao nosso tempo - resulta em trágicas consequências. A dependência química instalase à sombra de seu completo apagamento como sujeito, destino que ela partilha com Harry, o filho, usuário de heroína, denunciado à polícia tão logo procura o serviço de saúde para tratamento. Atravessamos um revival da velha tríade dos manicômios, prisões e conventos?

O capítulo de Tesser e Poli Neto, "Medicalização na infância e adolescência: histórias, práticas e reflexões de um médico da atenção primária", trabalha o conceito de medicalização a partir das vivências do personagem Julio, médico de saúde da família. Reitera a importância da atenção primária do Sistema Único de Saúde em filtrar os encaminhamentos desnecessários, muitos deles realizados por profissionais de educação. Essa função desmedicalizante é da máxima importância na diversificação das interpretações das queixas escolares, tarefa para a qual contribuem diversos capítulos, como o de M. P. R. de Souza, B. P. Souza, Cláudia Perrotta e Rejane Rubino. ${ }^{2}$ Destaca-se, também, outro relato de pesquisa de Collares e Moysés, ${ }^{3}$ o qual mostra que, segundo profissionais de educação pública da região de Campinas nos anos 1980, a família é principal causa do fracasso escolar, negligenciando-se razões políticas, econômicas e culturais mais complexas. É possível supor que a medicalização, cujos efeitos colaterais são desconhecidos pela população em geral, seja uma alternativa interessante justamente por fazer abstração da singularidade das queixas escolares - para todo problema, dispõe uma única estratégia: recorrer a serviços de saúde.

Os capítulos de Proença e Cunha, e o de Vicentin, ${ }^{4}$ contribuem significativamente para o conhecimento da expressão política da medicalização, mormente em São Paulo. Proença assinala a existência de nove projetos na Assembléia Legislativa Estadual que visam a criar serviços nas Secretarias da Educação ou da Saúde para atender a crianças com problemas escolares, protocolados pelos mais

Fractal, Rev. Psicol., v. 24 - n. 2, p. 429-434, Maio/Ago. 2012 
diversos partidos políticos. Estuda-se, ainda, a promoção dos transtornos e distúrbios criticados no livro (principalmente dislexia e TDAH) a objeto de atendimento no âmbito do Plano Nacional de Educação Especial. Argumento principal: o Estado não poderia negligenciar o oferecimento de atendimento "especializado" às crianças e adolescentes portadores desses (supostos) problemas de saúde.

Superando a escassez de pesquisas críticas sobre a medicalização (como se evidencia no capítulo de Garrido e Moysés), ${ }^{5}$ precisamos desenvolver quadros teórico-metodológicos vinculados a uma defesa dos direitos da infância e adolescência, rejeitando radicalmente rótulos medicalizantes como dislexia e TDAH. Opondo-se a tais noções, os capítulos de Moysés \& Collares alertam-nos: os rótulos não descrevem "transtornos culturais" ou "déficits", mas sim, falsos problemas, factóides que explicam o fracasso escolar de maneira extremamente simplista. Difundida por pesadas estratégias de marketing, a significação "TDAH" irradiou-se nas escolas e na vida cotidiana, substituindo outros rótulos fundamentados na individualização da queixa escolar. Criou-se a doença junto com a terapêutica dela, as quais passaram a mediar a formação da personalidade das crianças e adolescentes. Apresentar o TDAH como transtorno/déficit cultural parece-nos tornar admissível justamente o que é necessário criticar, ou seja, a existência do TDAH como psicopatologia, seja ela de natureza biológica ou cultural.

O livro representa uma notável coalizão de esforços de representantes de diversas profissões e abordagens teóricas contra a medicalização, transcendendo o âmbito da disputa corporativa em benefício da promoção dos direitos de crianças e adolescentes. Contribui para que a tarja preta da medicalização pela via do TDAH, dislexia e congêneres seja removida da nossa visão sobre a população em idade escolar, sem ofuscar as genuínas contribuições das ciências da saúde para a educação - como, por exemplo, a possibilidade de detecção precoce de necessidades educativas especiais (decorrentes, por exemplo, da deficiência visual e auditiva, da encefalopatia crônica infantil não-progressiva etc). Essas contribuições tornam possível a emergência de políticas para inclusão precoce dos indivíduos portadores de tais necessidades, sem que medicalizar seja um estratagema para mascarar os complexos e históricos problemas da educação nacional.

\section{Notas}

1 "Dislexia e TDAH: uma análise a partir da ciência médica".

${ }^{2}$ Respectivamente: "Retornando à patologia para justificar a não-aprendizagem escolar: a medicalização e o diagnóstico de transtornos de aprendizagem em tempos de neoliberalismo", "A medicalização do ensino comparece aos atendimentos psicológicos", "Possível intervenção fonoaudiológica em um caso de linguagem escrita", "Dislexia, processo de aquisição ou sintoma na escrita?".

3 "Preconceitos no cotidiano escolar: a medicalização do processo ensino-aprendizagem".

4"Projetos de lei e políticas públicas: o que a psicologia tem a propor para a educação?”, “'Os intratáveis': a patologização dos jovens em situação de vulnerabilidade".

5"Um panorama nacional dos estudos sobre a medicalização da aprendizagem de crianças em idade escolar". 


\section{REFERÊNCIAS}

REQUIEM for a dream. Directed by Darren Aronofsky. USA: Artisan Entertainment, 2001. 1 DVD. [Original film release 2000].

TESSER, C. D. Medicalização social (I): o excessivo sucesso do epistemicídio moderno na saúde. Interface Comunic, Saúde, Educ, Botucatu, SP, v. 10, n. 19, p. 61-76, jan./jun. 2006.

Recebido em: 10 de maio de 2012 Aceito em: 26 de junho de 2012 